\title{
Resposta da cultura de sementes de capim-mombaça a épocas e doses de adubação de boro
}

\section{The response of a Mombaça grass seed crop to timing and levels of boron fertilization}

\author{
Gleice Menezes de Almeida ${ }^{1 *}$; Marcos Weber do Canto ${ }^{2}$; \\ Armindo Barth $\mathrm{Neto}^{3}$; Antonio Carlos Saraiva da Costa ${ }^{4}$
}

\begin{abstract}
Resumo
Deficiência ou toxidez de boro (B) tem sido frequentemente mencionada em culturas de interesse agronômico. Neste experimento objetivou-se avaliar os efeitos de duas épocas (03 de março e na antese) e de quatro doses de aplicação foliar de B (Bórax) (equivalente a zero; 2,0; 4,0 e 6,0 kg ha-1) sobre os componentes da produtividade e da qualidade de sementes, na produtividade de sementes e sobre relações componentes-produtividade em capim-mombaça (Panicum maximum Jacq. cv. Mombaça). O experimento foi conduzido a campo. O delineamento experimental foi em blocos ao acaso, em esquema fatorial (2x4), com quatro repetições. Épocas e doses de B não tiveram efeito sobre a massa individual de perfilhos vegetativo e de perfilho com panícula e sobre os números de perfilhos vegetativos, com panícula e total. Houve interação significativa para a aplicação de B em 03 de março para os números de sementes aparentes e puras, panícula ${ }^{-1} \mathrm{e}$ área $^{-1}$, para a massa de mil sementes puras, produtividade de sementes aparentes, produtividade de sementes puras, índice de colheita e para a produtividade de sementes puras viáveis. As épocas e as doses de B não afetaram a pureza física e a germinação de sementes. Correlação significativa e alta foi obtida entre os números de sementes aparentes e puras por área e o índice de colheita com as produtividades de sementes aparentes e puras. Dose foliar de B de 4,0 $\mathrm{kg} \mathrm{ha}^{-1}$ pode ser indicada para ser aplicada em 03 de março em culturas de sementes de capim-mombaça. Palavras-chave: Adubação foliar de micronutriente, qualidade de sementes de gramínea tropical, Panicum maximum, produtividade de sementes
\end{abstract}

\begin{abstract}
Boron (B) deficiency has been frequently mentioned in crops of agronomic interest. This experiment aimed to evaluate the effects of two times (March 32008 and at anthesis) and four doses of foliar application of B (equivalent to 0, 2, 4 and $6 \mathrm{~kg} \mathrm{ha}^{-1}$ ) in Mombaça grass (Panicum maximum Jacq. cv. Mombaça) on components of seed yield and quality, seed yield, and relationships among yieldcomponents. The experimental design was a randomized block design with a factorial design $(2 \times 4)$, with four replications. The experiment was conducted in the field. The times and doses of B application had no effect on the mass of tillers vegetative and tillers with panicle, and numbers of vegetative tillers, tillers with panicle and total tillers. The interaction was significant in March 3, for the number of seeds apparent and pure, panicle ${ }^{-1}$ and area $^{-1}$, apparent seed yield, pure seed yield, harvest index, germinable
\end{abstract}

\footnotetext{
${ }^{1}$ Eng $^{\mathrm{a}}$ Agra , Discente do Curso de Mestrado em Agronomia, Universidade Estadual de Maringá, UEM, Maringá, PR. E-mail: gleice m.a.@hotmail.com

2 Eng $^{\circ}$ Agr ${ }^{\circ}$, Prof. Dr., Dept ${ }^{\circ}$ de Zootecnia, UEM, Maringá, PR. E-mail: mwcanto@uem.br

3 Eng $^{\circ} \mathrm{Agr}^{\circ}$, Discente do Curso de Doutorado em Produção Vegetal, Universidade Federal do Paraná, UFPR, Curitiba, PR. E-mail: arm barth@hotmail.com

4 Eng $^{\mathrm{o}}$ Agr ${ }^{\circ}$, Prof. Dr., Dept ${ }^{\circ}$ de Agronomia, UEM, Maringá, PR. E-mail: acscosta@uem.br

* Autor para correspondência
} 
seed yield, and for a one thousand seeds pure. The times and doses of B did not affect the physical purity and seed germination. A high correlation was obtained between the number of apparent and pure seeds per area and harvest index, with apparent seed yield and with pure seed yield. Levels of foliar B fertilization of $4.0 \mathrm{~kg} \mathrm{ha}^{-1}$ can be recommended to be applied in seed crops of Mombaça grass.

Key words: Foliar micronutrient fertilizer, seed quality tropical grass, Panicum maximum, seed yield

\section{Introdução}

Os efeitos negativos da deficiência ou da toxidez do $\mathrm{B}$ têm sido indicados como limitantes para o crescimento, desenvolvimento, produtividade (GUPTA, 2004; YAU; RYAN, 2008) e a qualidade de culturas agrícolas (BROWN et al., 2002; MIWA; FUJIWARA, 2010). Nos solos brasileiros, deduz-se que esse é um dos micronutrientes mais deficientes em culturas graníferas e forrageiras, relatos de sintomas visuais das deficiências não são incomuns. Além desse fato, o uso ininterrupto e maior de corretivos e de adubos poderia estar agravando no solo a insolubilização de micronutrientes (SOARES; CASAGRANDE; ALLEONI, 2008). Panicum maximum é uma gramínea africana muito utilizada em pastagens no Brasil e em regiões tropicais e subtropicais no mundo (MUIR; JANK, 2004). É fato inconteste, faz mais de duas décadas, que a ampliação do número de produtores especializados e de empresas do setor de sementes de forrageiras fez do Brasil um dos mais importantes produtor e exportador de sementes dessa gramínea. No Brasil, de acordo com Jank et al. (2008), o capim-mombaça é uma das cultivares de $P$. maximum anualmente mais semeadas, o seu montante de sementes comercializado ocupa a terceira posição dentre as gramíneas forrageiras tropicais, o que revela o amplo interesse de produtores em seu cultivo. Em muitas culturas agrícolas de relevância econômica, as respostas a épocas e a doses de B têm sido reportadas (SHORROCKS, 1997; GUPTA, 2004), mas em culturas de sementes de Panicum maximum não tem sido objeto da atenção de pesquisadores.

Nos textos científicos, técnicos e especializados, encontram-se relatos dos fatores de solo e dos efeitos de práticas de manejo e de adubação que podem se inter-relacionar, influenciando a disponibilidade de B à plantas; dentre estes, Shorrocks (1997) destacou, a textura e o teor de B no solo, a remoção nas colheitas de grãos e os efeitos adversos da calagem excessiva no $\mathrm{pH}$ do solo e da alta adubação fosfatada. Adicionalmente, em muitos trabalhos com o B conduzidos em casas de vegetação, as respostas foram contraditórias em relação aos trabalhos a campo (BROWN et al., 2002; GUERTAL, 2004; RERKASEM; JAMJOD, 2004; WONGMO; JAMJODS; RERKASEM, 2004).

A deficiência de B em plantas superiores resulta em efeitos desfavoráveis em funções nas células e em processos fisiológicos (DELL; HUANG, 1997; MARSCHNER, 1995). Uma característica de plantas submetidas a deficiências severas de B foi a paralisação do crescimento, em deficiências marginais, a redução de folhas em expansão, folhas de menor tamanho e de cor verde escura (DELL; HUANG, 1997). Em gramíneas, o sintoma mais comum da toxidez de B é a clorose nas margens e nas pontas de folhas (YAU; RYAN, 2008). Brown et al. (2002) e Miwa e Fujiwara (2010); entre outros, comentam que as exigências de B nas culturas podem ser distintas nas fases vegetativas e reprodutivas. $\mathrm{Na}$ reprodução de plantas, atribuiu-se ao B papel ativo na síntese de proteínas, na translocação de carboidratos, no crescimento do tubo polínico e na retenção de sementes (MIWA; FUJIWARA, 2010).

Os componentes de qualidade de sementes em gramíneas forrageiras podem ser descritos pela pureza física, massa de mil sementes, MS de plântulas germinadas, teor de nitrogênio e porcentagens de sementes leves e de germinação (COCKSON; ROWARTH; CAMERON, 2000). $\mathrm{Na}$ Índia, em variedades de sorgo [Sorghum bicolor (L.) Moench], a aplicação foliar de 1,0 g $1^{-1}$ de bórax, em estádio reprodutivo (70 dias após 
semeadura), incrementou a produtividade e o vigor de germinação de sementes (MISRA; SINHA; TOMER, 1991). Esses efeitos, no entanto, diferiram entre as variedades de sorgo testadas.

Em cereais de inverno, especialmente em trigo (Triticum aestivum L.), Rerkasem e Janjod (2004) citam que o número de grãos espiga ${ }^{-1}$ foi o componente mais sensível a deficiência de $\mathrm{B}$, devido aos efeitos adversos na viabilidade do pólen e sobre processos de fertilização. Em variedades de sorgo, a adubação boratada propiciou aumento no número de sementes panícula-1 ${ }^{-1}$ (MISRA; SINHA; TOMER, 1991). Na Thailândia, Lordkaew et al. (2013), ao avaliarem efeitos do B (0 e $10 \mu \mathrm{M}$ B) utilizando vasos com soluções completas de nutrientes, em três variedades de arroz (Oryza sativa L.) e em duas estações de plantio, encontraram correlação alta e positiva entre o peso de grãos $\left(g\right.$ planta $\left.^{-1}\right)$ com o vingamento de grãos (\%) e com o número de espiguetas planta $^{-1}$. Eles verificaram, no entanto, que o vingamento de grãos, o número de espiguetas planta $^{-1}$ e o peso de grãos não se correlacionaram com o número de perfilhos planta ${ }^{-1}$ e com o peso seco $\left(\right.$ g planta $\left.^{-1}\right)$.

Em capim-mombaça, o número de sementes panícula $^{-1}$ foi um dos componentes mais determinantes na produtividade de sementes (BARTH NETO et al., 2010; CANTO et al., 2012). Torres et al. (2009), ao investigarem em capimtanzânia (Panicum maximum Jacq. cv. Tanzânia-1) doses de nitrogênio até $200 \mathrm{~kg} \mathrm{ha}^{-1}$, constataram correlação entre o número de sementes panícula ${ }^{-1}$ com as produtividades de sementes total e de puras. Monteiro, Favoretto e Reis (1984), ao investigarem em capim-colonião (Panicum maximum Jacq. cv. Colonião) épocas de rebaixamento e doses de nitrogênio até $145 \mathrm{~kg} \mathrm{ha}^{-1}$, notaram correlação significativa e positiva entre o vigor de perfilhos com a produção de sementes aparentes e com a produção de sementes inflorescência ${ }^{-1}$.

Diante do incremento que o B pode causar na produtividade e na qualidade de sementes às culturas de gramíneas, este trabalho teve como propósito avaliar os efeitos de épocas e de doses de B sobre os componentes da produtividade e da qualidade de sementes, na produtividade de sementes e relações componentes-produtividade em capim-mombaça.

\section{Material e Métodos}

O experimento foi instalado no Campus da Universidade Estadual de Maringá (UEM), em Umuarama, no Noroeste do Paraná (longitude $53^{\circ} 17^{\prime}$, latitude $23^{\circ} 44^{\prime \prime}$ e altitude de $480 \mathrm{~m}$ ), em um solo Argissolo Vermelho Amarelo distrófico (SANTOS et al., 2006). O clima na região é 'Cfa' de acordo com Köeppen, com média anual de chuvas por volta de $1.623 \mathrm{~mm}$. Os meses de outubro a janeiro são os mais chuvosos, as médias são por volta de $170 \mathrm{~mm}$ (WREGE et al., 2011). As médias anuais de temperaturas média, máxima e mínima são 22,$1 ; 27,7$ e $17,8^{\circ} \mathrm{C}$, respectivamente. Os dados climáticos foram obtidos na Estação Meteorológica do Simepar, a cerca de $10 \mathrm{~km}$ do campo experimental.

O delineamento experimental de blocos completos casualizados foi usado em esquema fatorial $(2 \times 4)$, com quatro repetições. Os tratamentos consistiram de duas épocas, em 03 de março e na antese (17/5/2008), e de quatro doses de aplicação foliar de $\mathrm{B}$ (ácido bórico, $\mathrm{H}_{3} \mathrm{BO}_{3}$ ), as quais supriram o equivalente a zero; 2,0; 4,0 e 6,0 $\mathrm{kg} \mathrm{ha}^{-1}$. O B foi aplicado com pulverizador costal. O produto comercial ácido bórico continha $170 \mathrm{~g}$ de $\mathrm{B} \mathrm{L}^{-1}$ e foi diluído em $200 \mathrm{~L}$ de água. Definiu-se a antese quando por volta de $30 \%$ dos perfilhos com panículas examinados ao acaso na parcela possuíam espiguetas com anteras exteriorizadas. As parcelas experimentais tiveram dimensão de 6,0 x 4,0 m (24 $\left.\mathrm{m}^{2}\right)$.

No estabelecimento da forrageira (14/9/2006) foi incorporado ao solo $180 \mathrm{~kg} \mathrm{ha}^{-1} \mathrm{de}_{2} \mathrm{O}_{5}$ (superfosfato simples) e $60 \mathrm{~kg} \mathrm{ha}^{-1}$ de $\mathrm{K}_{2} \mathrm{O}$ (cloreto de potássio). $\mathrm{Na}$ semeadura, realizada em 25 de setembro de 2006, 6,0 $\mathrm{kg} \mathrm{ha}^{-1}$ de sementes puras foram aplicadas 
ao solo e, a seguir, foram incorporadas a $1,5 \mathrm{~cm}$ no solo com grade niveladora. Em janeiro de 2007 as parcelas foram delimitadas e os pastos foram roçados e adubados com $80 \mathrm{~kg} \mathrm{ha}^{-1}$ de nitrogênio (ureia). Nas estações do outono e do inverno de 2007 as plantas invasoras foram manualmente removidas nas parcelas experimentais. A coleta de solo foi em 3/9/2007 à profundidade de zero a $20 \mathrm{~cm}$. As características químicas do solo foram: $\mathrm{pH}$ em $\mathrm{H}_{2} \mathrm{O}$, 5,$6 ; \mathrm{Al}^{3+}, 0,1 \mathrm{cmol}_{\mathrm{c}} \mathrm{dm}^{-3} ; \mathrm{H}+\mathrm{Al}^{3+}, 3,97 \mathrm{cmol}_{\mathrm{c}} \mathrm{dm}^{-3}$; $\mathrm{Ca}^{2+}+\mathrm{Mg}^{2+}, 1,71 \mathrm{cmol}_{\mathrm{c}} \mathrm{dm}^{-3} ; \mathrm{K}^{+}, 0,13 \mathrm{cmol}_{\mathrm{c}} \mathrm{dm}^{-3} ; \mathrm{P}$, $10,4 \mathrm{mg} \mathrm{dm}^{-3} ; \mathrm{Zn}, 10,9 \mathrm{mg} \mathrm{dm}^{-3} ; \mathrm{Cu}, 5,70 \mathrm{mg} \mathrm{dm}^{-3}$; $\mathrm{Mn}, 32 \mathrm{mg} \mathrm{dm}{ }^{-3}$; C, 11,06 $\mathrm{g} \mathrm{dm}^{-3}$; B, 0,08 mg dm3. O B foi determinado usando-se a extração com água quente (BERGER; TRUOG, 1939). A textura do solo na profundidade de $0-20 \mathrm{~cm}$ teve $780 \mathrm{~g} \mathrm{~kg}^{-1}$ de areia, $140 \mathrm{~g} \mathrm{~kg}^{-1}$ de argila e $80 \mathrm{~g} \mathrm{~kg}^{-1}$ de silte. Em 25/10/2007, para a condução do trabalho foram aplicados em cobertura superfosfato simples (100 $\mathrm{kg} \mathrm{ha}{ }^{-1}$ de $\mathrm{P}_{2} \mathrm{O}_{5}$ ) e cloreto de potássio (60 $\mathrm{kg} \mathrm{ha}^{-1} \mathrm{de}$ $\mathrm{K}_{2} \mathrm{O}$ ). O capim-mombaça exige solos com condição de fertilidade média a alta (JANK et al., 2008). As precauções sugeridas por Bell (1997) para experimentos a campo com o B foram efetuadas, sobretudo, quanto a nutrientes que poderiam limitar o crescimento e o desenvolvimento da cultura.

O experimento foi iniciado com o corte de uniformização do pasto em 20/11/2007 e perdurou até a colheita, em 26/5/2008. No período de 20/11/2007 a $15 / 2 / 2008$, nas parcelas quando a altura do pasto atingia $90 \mathrm{~cm}$ a forragem era cortada a $30 \mathrm{~cm}$ do solo com roçadeira costal e removida. Em 15 de fevereiro de 2008 fez-se nas parcelas o último corte de rebaixamento a $30 \mathrm{~cm}$ do solo. As adubações de nitrogênio (uréia) de $50 \mathrm{~kg} \mathrm{ha}^{-1}(3 / 12 / 2007)$ e $150 \mathrm{~kg}$ $\mathrm{ha}^{-1}(10 / 1 / 2008)$ foram a lanço e em cobertura. Nas parcelas, as observações do início de florescimento eram realizadas duas vezes por semana, a partir de $15 / 3 / 2008$, e foi definida quando a cultura atingiu entre 5,0 a 10 panículas totalmente emergidas $\mathrm{m}^{-2}$. A época de colheita foi predefinida em 38 dias após início de florescimento, conforme indicam Condé e Garcia (1985).
As seguintes mensurações foram feitas na colheita: os perfilhos vegetativos e os com panícula foram contados e cortados rente ao solo em duas áreas de $1,0 \mathrm{~m}^{2}(1,0 \times 1,0 \mathrm{~m})$, delimitadas por quadrado na porção central da parcela. Essas amostras foram secas em estufa de ar forçado a $60^{\circ} \mathrm{C}$ até massa constante, obtendo-se assim a estimativa da matéria seca (MS) $\mathrm{ha}^{-1}$. Em cada parcela foram cortados rente ao solo e colhidos 20 perfilhos, em estádio vegetativo e com panícula, representativos do tamanho médio na parcela e secos em estufa até massa constante a $60^{\circ} \mathrm{C}$ para avaliação da massa/perfilho. $\mathrm{O}$ número de sementes panícula ${ }^{-1}$ foi determinado com o corte de 10 panículas representativas por parcela, que em setembro de 2008 foram trilhadas manualmente. Nessas amostras, 100 sementes de cada parcela, de aparentes e de puras, foram utilizadas na avaliação das respectivas massa de mil sementes.

As cariopses cheias (sementes puras) foram separadas manualmente das vazias. A germinação de sementes foi avaliada oito meses após a colheita, de acordo com regras de análise (BRASIL, 2009), usando-se caixas transparentes tipo "gerbox", folhas de germiteste umedecidas com $\mathrm{KNO}_{3}$ a $0,2 \%$ e regimes alternados de temperatura de $15-35^{\circ} \mathrm{C}$. O cômputo das plântulas normais foi aos 10 e aos 28 dias. A porcentagem de germinação de sementes foi obtida pela razão:

Germinação de sementes $=$ (número total de plântulas normais/número total de sementes) x 100 .

A produtividade de sementes aparentes foi estimada pela multiplicação, dos números de perfilhos com panícula, de sementes aparentes panícula $^{-1}$ e da massa de mil sementes aparentes. A produtividade de sementes puras foi calculada com a multiplicação dos números de perfilhos com panícula, das sementes puras panícula-1 e da massa de mil sementes puras. O índice de colheita (\%) foi obtido dividindo-se a produtividade de sementes puras pela $\mathrm{MS} \mathrm{ha}^{-1}$. A produtividade de sementes puras viáveis foi calculada com a multiplicação da germinação de sementes (\%) pela produtividade de sementes puras. 
Os dados foram submetidos à análise da variância e as médias de épocas de aplicação de B foram comparadas pelo teste F (SAS INSTITUTE, 2002). Análises de regressão foram realizadas com variáveis dependentes que apresentaram efeitos do B e interação, foram testados o modelo linear e o quadrático. Médias de produtividades de sementes e de seus componentes foram usadas em análises de correlação de Pearson.

\section{Resultados e Discussão}

Pode-se observar que as condições climáticas no período experimental (Tabela 1) foram próximas das frequentemente verificadas no Noroeste do Paraná (WREGE et al., 2011), e de maneira geral beneficiaram o crescimento e o desenvolvimento reprodutivo da cultura. As médias de temperaturas foram próximas até abril (meados de outono). Em maio, durante o florescimento até a colheita, as médias de temperaturas se reduziram. A distribuição da precipitação pluvial provavelmente foi suficiente para suprir as exigências hídricas da cultura (MUIR; JANK, 2004). O baixo volume de chuvas em março pode ter tido pouco efeito adverso sobre o desenvolvimento de panículas e sementes.

Tabela 1. Temperatura do ar, precipitação pluviométrica (PP), umidade relativa do ar (U.R.) e insolação no período experimental.

\begin{tabular}{ccccccc}
\hline Mês/ano & $\begin{array}{c}\text { Máxima } \\
\text { média }\end{array}$ & $\begin{array}{c}\text { Temperatura } \\
\text { Mínima média } \\
\left({ }^{\circ} \mathrm{C}\right)\end{array}$ & Média & $\begin{array}{c}\text { PP } \\
\text { Total Mensal } \\
(\mathrm{mm})\end{array}$ & $\begin{array}{c}\text { U.R. } \\
\text { Média } \\
(\%)\end{array}$ & $\begin{array}{c}\text { Insolação } \\
\text { Média } \\
\left(\mathrm{h} \mathrm{dia}^{-1}\right)\end{array}$ \\
\hline Nov./2007 & 30,9 & 20,3 & 25,6 & 236,6 & 49,9 & 7,8 \\
Dez./2007 & 31,9 & 19,7 & 25,8 & 142,1 & 60,8 & 7,4 \\
Jan./2008 & 30,9 & 19,8 & 25,3 & 91,7 & 62,2 & 6,2 \\
Fev./2008 & 32,0 & 19,4 & 25,7 & 223,8 & 59,9 & 7,3 \\
Mar./2008 & 30,7 & 18,2 & 24,5 & 49,8 & 59,0 & 8,2 \\
Abr./2008 & 31,7 & 17,4 & 24,6 & 100,5 & 70,6 & 6,7 \\
Maio/2008 & 26,4 & 15,0 & 20,7 & 98,3 & 75,9 & 6,7 \\
\hline
\end{tabular}

Fonte: Estação Climatológica do SIMEPAR.

Após uma semana da adubação boratada, em ambas as épocas avaliadas, sintomas de toxidez (clorose) foram vistos nas margens e pontas das folhas resultantes da alta disponibilidade de $\mathrm{B}$ da adubação foliar. Esses efeitos, aparentemente, foram mais evidentes nas parcelas em que foram aplicadas as taxas mais altas de $\mathrm{B}$, conforme já observado por Oertli, Lunt e Youngner (1961). Em campos de sementes, após a colheita, o corte mecânico ou o pastejo dos animais pode remover a forragem com os sintomas de toxidez.
A massa individual de perfilho vegetativo e com panícula, os números de perfilhos vegetativos, com panícula e total, a porcentagem de perfilhos com panícula e a quantidade de $\mathrm{MS} \mathrm{ha}^{-1}$ não foram influenciados $(\mathrm{P}>0,05)$ pelas épocas e pelas doses foliares de B, a interação não foi significativa (Tabela 2). As médias de massa de perfilho vegetativo e com panícula e de números de perfilhos vegetativos, com panícula e total e de $\mathrm{MS} \mathrm{ha}^{-1}$ foram, respectivamente, 6,4 e 19 g MS perfilho-1 $^{-1}$ 336, 30 e 366 perfilhos $\mathrm{m}^{-2}$ e $18.411 \mathrm{~kg}$ de $\mathrm{MS} \mathrm{ha}^{-1}$. Entretanto, contatou-se que a interação épocas e doses de aplicação de B em 03 de março foi significativa para os números de sementes aparentes e puras panícula ${ }^{-1}$. 
Tabela 2. Análise estatística da massa de perfilho vegetativo (MPV), massa de perfilho com panícula (MPP), número de perfilhos vegetativos (NPV), número de perfilhos com panícula (NPP), número total de perfilhos (NTP), porcentagem de perfilhos com panícula (PP), matéria seca (MS) ha ${ }^{-1}$, número de sementes aparentes panícula-1 $(\mathrm{NSAP})$, número de sementes puras panícula-1 $(\mathrm{NSPP})$.

\begin{tabular}{lccccccccc}
\hline & MPV & MPP & NPV & NPP & NTP & PP & MS ha $^{-1}$ & NSAP & NSPP \\
\hline Ëpoca & $\mathrm{ns}$ & $\mathrm{ns}$ & $\mathrm{ns}$ & $\mathrm{ns}$ & $\mathrm{ns}$ & $\mathrm{ns}$ & $\mathrm{ns}$ & $*$ & $*$ \\
Boro & $\mathrm{ns}$ & $\mathrm{ns}$ & $\mathrm{ns}$ & $\mathrm{ns}$ & $\mathrm{ns}$ & $\mathrm{ns}$ & $\mathrm{ns}$ & $*$ & $*$ \\
Época x boro & $\mathrm{ns}$ & $\mathrm{ns}$ & $\mathrm{ns}$ & $\mathrm{ns}$ & $\mathrm{ns}$ & $\mathrm{ns}$ & $\mathrm{ns}$ & $*$ & $*$ \\
\hline
\end{tabular}

** significativo a $1 \%$ de probabilidade pelo teste $\mathrm{F}$; *: significativo a $5 \%$ de probabilidade pelo teste $\mathrm{F}$; NS: não significativo a $5 \%$ de probabilidade pelo teste $\mathrm{F}$.

Fonte: Elaboração dos autores.

A falta de resposta ao B na aplicação em 03 de março pode ser atribuída, sobretudo, ao teor de $\mathrm{B}$ no solo e à textura e ao $\mathrm{pH}$ no solo, que podem ter provido taxas de absorção de $\mathrm{B}$ à cultura que atendeu as exigências de produção desses caracteres. Os números de perfilhos vegetativos e com panícula e de MS ha ${ }^{-1}$ verificados são próximos dos reportados nas doses de nitrogênio altas por Barth Neto et al. (2010) e por Canto et al. (2012), que avaliaram a produção de sementes do capim-mombaça rebaixado em meados de fevereiro. Neste estudo constatamos que o capim-mombaça pode tolerar alta dose foliar de $\mathrm{B}$, as injúrias não tiveram efeito sobre a demografia de perfilhos e sobre a quantidade de MS ha-1 ${ }^{-1}$ No entanto, no caso deste experimento, a toxidez notada nas folhas mostrou que o capimmombaça foi sensível as doses mais altas de B.

Era esperada a falta de efeito da aplicação de $\mathrm{B}$ na antese nesses componentes de produtividade de sementes. Além dos aspectos já comentados, teor de $\mathrm{B}$ no solo, à textura e o $\mathrm{pH}$ no solo, o $\mathrm{B}$ aplicado na fenofase da antese pode influir pouco sobre o acúmulo de MS e sobre o perfilhamento do capim-mombaça, que é planta de dia curto, portanto sensível ao fotoperíodo e que se encontrava em final de ciclo. Na região Sul do Brasil, a partir de fevereiro, verifica-se redução gradativa no comprimento de dia e alterações em variáveis climáticas e, em consequência, nos perfilhos de $P$. maximum iniciase o alongamento dos entrenós, sendo o crescimento paralisado na medida em que os meses de outono se aproximam (CANTO, 2003).
$\mathrm{Na}$ área experimental o solo apresentava teor de B de 0,08 $\mathrm{mg} \mathrm{dm}^{-3}$. Reisenauer, Walsh e Roeft (1973) sugeriram para as culturas agrícolas, de modo genérico, ou seja, sem distinguir possíveis diferenças em exigências de $B$ nas fases vegetativas ou reprodutivas, que o teor crítico de $\mathrm{B}$ no solo é $0,1 \mathrm{mg} \mathrm{kg}^{-1}$. Teores de B no solo inferiores a 0,1 $\mathrm{mg} \mathrm{dm}{ }^{-3}$ são por iguais considerados baixos pela Comissão de Química e Fertilidade do Solo - RS/ SC (2004). Sabe-se que é curta a amplitude de B no solo que pode causar deficiência ou toxidez nas plantas (SHORROCKS, 1997). É importante frisar, que os resultados nesses parâmetros não devem ser extrapolados para solos mais argilosos e submetidos à aplicação de calcário ou com o pH alto, onde é maior a probabilidade de ocorrer deficiências graves de B, e também para solos arenosos com teores baixos de matéria orgânica, que tendem a ter concentração baixa de B (ROSOLEM; BÍSCARO, 2007).

Oertli, Lunt e Youngner (1961), em gramíneas de estação fria supridas com doses altas de B, relatam que a necrose nas margens e extremidades superiores das folhas não causou efeito no acúmulo de forragem. Peterson e Newman (1976) em Festuca arundinaceae L. Schreb., em experimento em vasos, não obtiveram resposta na absorção de B e na produção de MS em solos com $\mathrm{pH}$ que variaram entre 4,7 a 6,3 e onde foram testados doses de B até $20 \mathrm{~kg} \mathrm{ha}^{-1}$. A falta de efeito no número de perfilhos e na produção de MS foi também reportada por Guertal (2004), em experimentos em casa de vegetação 
e a campo, ao avaliarem em cultivares de capim Agrostis palustris Huds. doses de B até 2,2 $\mathrm{kg} \mathrm{ha}^{-1}$. No presente trabalho, a falta de efeito da aplicação de $\mathrm{B}$ em 03 de março nos caracteres vegetativos é consistente com os resultados constatados por Lordkaew et al. (2011), em milho (Zea mays L.), que não verificaram efeito do $\mathrm{B}$ na $\mathrm{MS}$ planta $^{-1}$ (parte aérea e raízes) e na razão raiz:parte aérea. Rerkasem e Janjod (2004) ao revisarem deficiências de B em trigo, mencionam que são raros os efeitos do baixo $\mathrm{B}$ em caracteres vegetativos, como no número de perfilhos vegetativos e na quantia de palha produzida.

A interação épocas e doses de aplicação de B em 03 de março foi significativa para os números de sementes aparentes e puras panícula-1 ${ }^{-1}$ Figura 1). Houve interação significativa para épocas e doses de $\mathrm{B}$ nos números de sementes aparentes e puras, expressos por área $\left(\mathrm{m}^{2}\right)$, e para as produtividades de sementes aparentes, puras e puras viáveis e índice de colheita (Tabela 3, Figura 2). Entretanto, na época de adubação na antese, a interação e as épocas e as doses de $\mathrm{B}$ não teve efeito significativo $(\mathrm{P}>0,05)$ nos números de sementes aparentes e puras, panícula ${ }^{-1}$ e área ${ }^{-1}$, nas produtividades de sementes aparentes, puras e puras viáveis e no índice de colheita, cujas médias foram de 198 e 78 sementes panícula ${ }^{-1}$ e 6.197 e 2.465 sementes $\mathrm{m}^{-2}, 64,4,25,6$ e 4,5 kg ha-1 e 0,138 , respectivamente. Os tratamentos de $\mathrm{B}$ não afetaram os componentes da qualidade de sementes pureza física e germinação de sementes (Tabela 3). As médias de pureza física e de germinação de sementes foram de 40 e $18 \%$, respectivamente. A interação época e doses de B em 03 de março foi significativa para a massa de mil sementes puras (Figura 3). Na época de aplicação na antese, não se obteve interação significativa e as épocas e as doses de $\mathrm{B}$ não afetaram essa variável, a média de massa de mil sementes puras foi de $1,043 \mathrm{~g}$.
Esses achados comprovam que em capimmombaça o $\mathrm{B}$ pode propiciar maior número de sementes panícula ${ }^{-1}$, tal como observado para o número de grãos inflorescência ${ }^{-1}$ em outros cereais (SHORROCKS, 1997; RERKASEM; JAMJOD, 2004; WONGMO; JAMJOD; RERKASEM, 2004; LORDKAEW et al. 2012, 2013). Recomendações de adubação em culturas de sementes de capimmombaça para alta produtividade devem considerar esses efeitos. A deficiência de B, de acordo com Lordkaew et al. (2013), é definida pela resposta da cultura a adubação boratada.

É possível que o incremento no número de sementes puras panícula ${ }^{-1}$, na aplicação de B em 03 de março, deveu-se a melhorias no desenvolvimento e na germinação de grãos de pólen, no crescimento do tubo polínico, desenvolvimento de anteras e em outros processos reprodutivos, pois segundo Brown et al. (2002), em muitas espécies de plantas, a falta de $\mathrm{B}$ pode inibir estes processos e o vingamento de sementes.

No presente trabalho, a resposta ao B em 03 de março na produtividade de sementes puras pode estar também relacionada à remoção das plantas nas parcelas, realizadas até o corte de rebaixamento em 15 de fevereiro. Shorrocks (1997) notou que a exportação de $\mathrm{B}$ em culturas de milho $\left(6,0 \mathrm{t} \mathrm{ha}^{-1} \mathrm{de}\right.$ grãos) e de trigo (3,0 t ha- ${ }^{-1}$ de grãos) não excedeu, respectivamente, a 25 e a $30 \mathrm{~g} \mathrm{ha}^{-1}$. Entretanto, de acordo com o autor, isso não impede que deficiências possam ocorrer devido às exigências específicas na fertilização e no vingamento de sementes. Os efeitos do B mencionados por Brown et al. (2002), neste trabalho podem não ter tido efeito do $\mathrm{B}$ aplicado na antese na produtividade de sementes puras em razão da alta variabilidade na formação de sementes nas panículas que se observa em $P$. maximum, encontrando-se espiguetas vazias, em início de enchimento e com endosperma constituído. 
Tabela 3. Análise estatística do número de sementes aparentes área ${ }^{-1}$ (NSAA), número de sementes puras área-1 (NSPA), produtividade de sementes aparentes (PSA), produtividade de sementes puras (PSP), produtividade de sementes puras viáveis, índice de colheita (IC), pureza física (PF), massa de mil sementes puras (MMS) e porcentagem de germinação de sementes (GS).

\begin{tabular}{lccccccccc}
\hline & NSAA & NSPA & PSA & PSP & PSPV & IC & PF & MMS & GS \\
\hline Ëpoca & $*$ & $*$ & $*$ & $*$ & $*$ & $*$ & ns & $* *$ & ns \\
Boro & $*$ & $*$ & $*$ & $*$ & $*$ & $*$ & ns & $* *$ & ns \\
Época x boro & $*$ & $*$ & $*$ & $*$ & $*$ & $*$ & ns & $* *$ & ns \\
\hline
\end{tabular}

** significativo a $1 \%$ de probabilidade pelo teste $\mathrm{F}$; *: significativo a $5 \%$ de probabilidade pelo teste $\mathrm{F}$; NS: não significativo a $5 \%$ de probabilidade pelo teste $\mathrm{F}$.

Fonte: Elaboração dos autores.

Figura 1. Número de sementes aparentes panícula ${ }^{-1}$, número de sementes puras panícula ${ }^{-1}$, número de sementes aparentes área ${ }^{-1}$ e número de sementes puras área ${ }^{-1}$ em função da dose de boro aplicada em 03 de março.
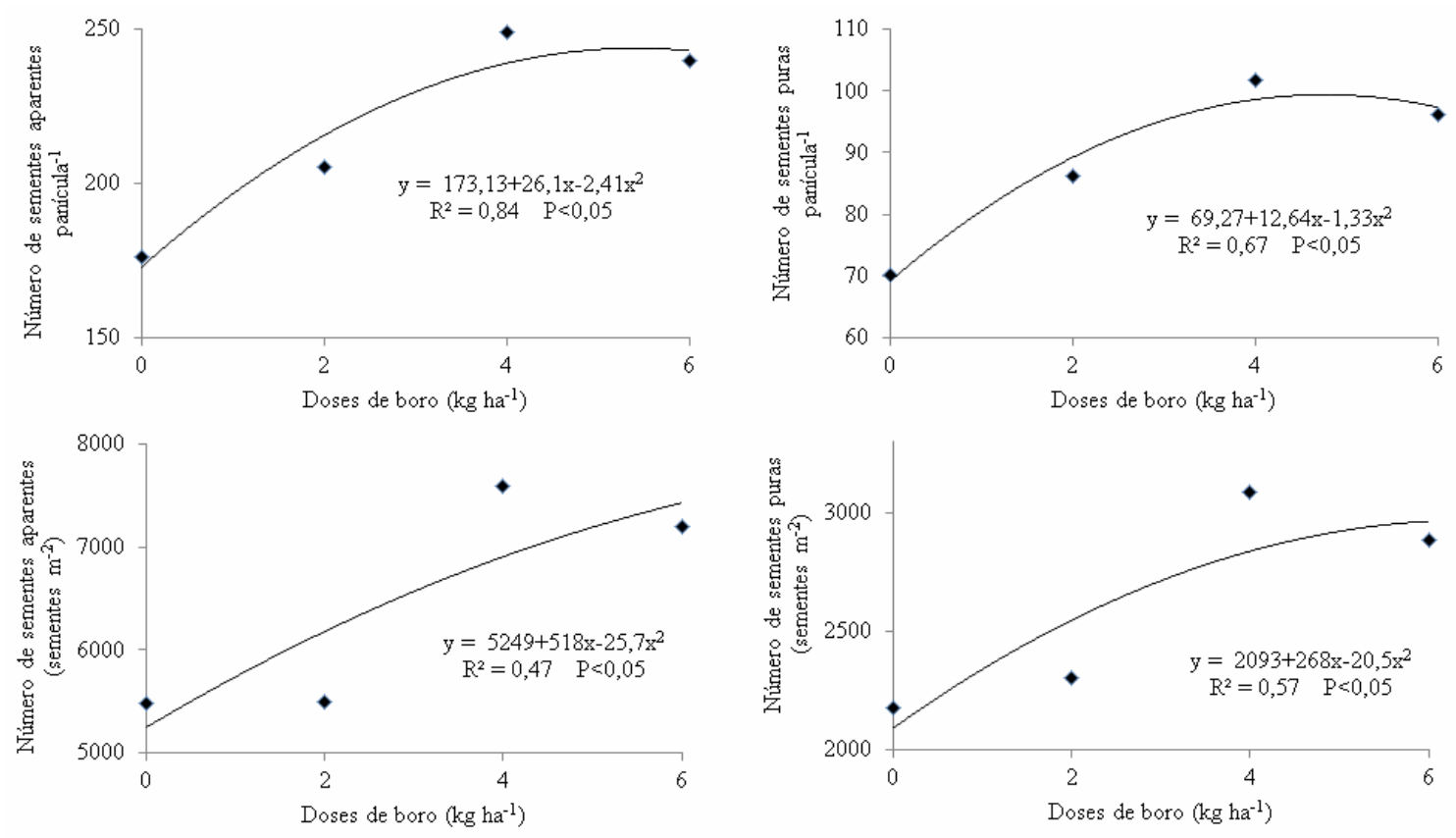

Fonte: Elaboração dos autores. 
Figura 2. Produtividade de sementes aparentes, produtividade de sementes puras, índice de colheita e produtividade de sementes puras viáveis em função da dose de boro aplicada em 03 de março.
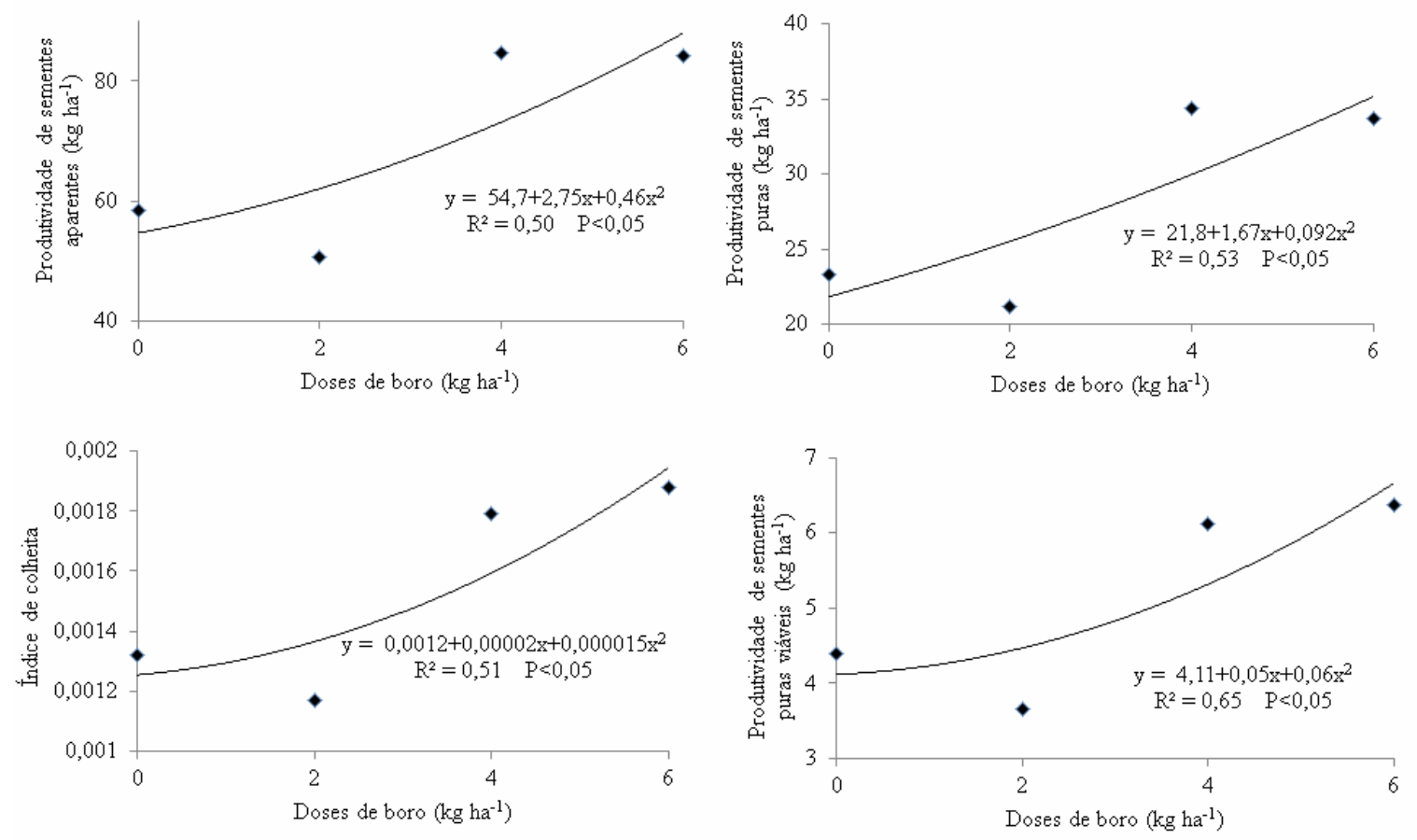

Fonte: Elaboração dos autores.

De um ponto de vista econômico, foram aceitáveis os aumentos na produtividade de sementes aparentes e puras observados com o B aplicado em 03 de março. Na aplicação de B em 03 de março, os valores máximos preditos de números de sementes aparentes e puras panícula ${ }^{-1}$ foram de 243,8 (5,4 kg ha-1 de B) e 99,3 (4,7 $\mathrm{kg} \mathrm{ha}^{-1}$ de B) sementes panícula ${ }^{-1}$ e de produtividade de sementes aparentes foi de $67,0 \mathrm{~kg} \mathrm{ha}^{-1}\left(3,0 \mathrm{~kg} \mathrm{ha}^{-1}\right.$ de B). Nessa mesma época de aplicação, as médias observadas de produtividade de sementes puras nas doses de $\mathrm{B}$ zero, 2, 4 e $6 \mathrm{~kg} \mathrm{ha}^{-1}$ foram, respectivamente, 23,3; 21,2; 34,3 e 33,7 $\mathrm{kg} \mathrm{ha}^{-1}$. Esses resultados sugerem que a dose foliar de $\mathrm{B}$ de $4,0 \mathrm{~kg} \mathrm{ha}^{-1}$ aplicada no início de março, previamente ao início de florescimento, pode ser preconizada em culturas de sementes de capim-mombaça. Entretanto, os mecanismos que causam as diferentes respostas no desenvolvimento de sementes do capim-mombaça ao B permanecem não explicados. Os resultados de produtividades

de sementes aparentes e puras sugerem também que pesquisas adicionais devem ser feitas com o B em campos de sementes das demais cultivares de Panicum maximum e em outros tipos de solos, inclusive com a avaliação residual do B sobre as colheitas subsequentes.

A efetividade da adubação de B em 03 de março sobre a massa de mil sementes puras pode ser atribuída a efeitos específicos em processos reprodutivos, especialmente no desenvolvimento de flores e sementes (SHORROCKS, 1997; BROWN et al., 2002) e em outros processos fisiológicos (BROWN et al., 2002; MIWA; FUJIWARA, 2010). Em Panicum maximum, com o B, inexistem estudos sobre a qualidade de sementes. A baixa germinação de sementes pode ser devido à imaturidade das sementes e a dormência residual que reduzem a germinação de sementes colhidas de panículas em Panicum maximum (MUIR; JANK, 2004; DIAS; ALVES, 2008; CANTO et al., 2012). 
A correlação entre a massa de mil sementes puras com o número de sementes aparentes panícula ${ }^{-1}$ foi significativa e baixa (Tabela 4). As correlações entre os demais componentes de produtividade de sementes não foram significativas.

Figura 3. Massa de mil sementes puras em funcão da dose de boro aplicada em 03 de março.

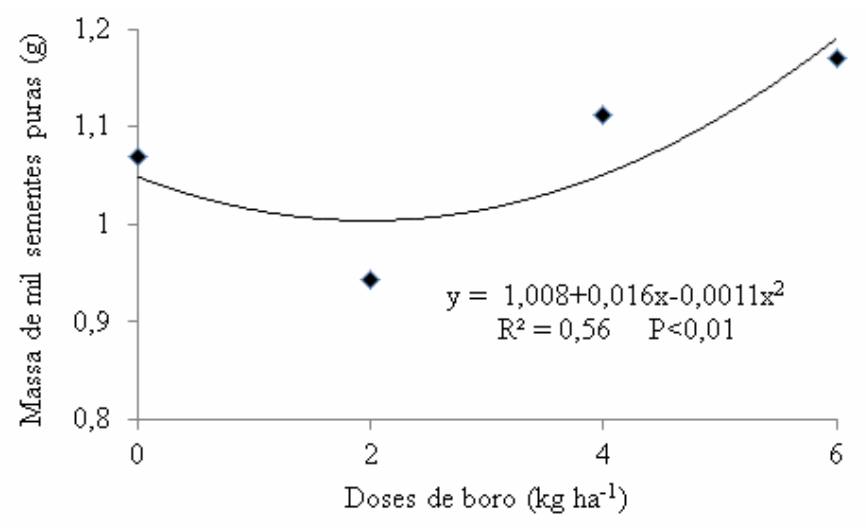

Fonte: Elaboração dos autores.

Tabela 4. Coeficiente de correlação de Pearson entre componentes da produtividade e da qualidade de sementes com a produtividade de sementes aparentes (PSA), produtividade de sementes puras (PSP) e com a produtividade de sementes puras viáveis (PSPV), em capim-mombaça em função de épocas e doses de boro.

\begin{tabular}{|c|c|c|c|}
\hline & PSA & $\begin{array}{c}\text { PSP } \\
\left(\mathrm{kg} \mathrm{ha}^{-1}\right)\end{array}$ & PSPV \\
\hline Massa de perfilho com panícula (g MS perfilho-1) & $-0,157 \mathrm{~ns}$ & $-0,152 \mathrm{~ns}$ & $-0,202 \mathrm{~ns}$ \\
\hline Número de perfilhos vegetativos (perfilhos $\mathrm{m}^{-2}$ ) & $-0,375^{*}$ & $-0,272 \mathrm{~ns}$ & $-0,459 * *$ \\
\hline Número de perfilhos com panículas (perfilhos $\mathrm{m}^{-2}$ ) & $0,425^{*}$ & $0,329 \mathrm{~ns}$ & $0,268 \mathrm{~ns}$ \\
\hline Número total de perfilhos (perfilhos $\mathrm{m}^{-2}$ ) & $-0,364 *$ & $-0,263 \mathrm{~ns}$ & $-0,452 * *$ \\
\hline Perfilhos com panícula (\%) & $0,323 \mathrm{~ns}$ & $0,347 \mathrm{~ns}$ & $0,282 \mathrm{~ns}$ \\
\hline Matéria seca $\left(\mathrm{kg} \mathrm{ha}^{-1}\right)$ & $-0,021 \mathrm{~ns}$ & $0,056 \mathrm{~ns}$ & $0,129 \mathrm{~ns}$ \\
\hline Número de sementes aparentes por panícula & $0,767 * *$ & $0,776 * *$ & $0,708 * *$ \\
\hline Número de sementes puras por panícula & $0,570 * *$ & $0,745 * *$ & $0,624 * *$ \\
\hline Número de sementes aparentes (sementes $\mathrm{m}^{-2}$ ) & $0,918^{* *}$ & $0,855^{* *}$ & $0,759 * *$ \\
\hline Número de sementes puras $\left(\right.$ sementes $\left.\mathrm{m}^{-2}\right)$ & $0,815^{* *}$ & $0,912 * *$ & $0,759 * *$ \\
\hline Índice de colheita $(\%)$ & $0,911 * *$ & $0,936 * *$ & $0,754 * *$ \\
\hline Sementes puras $(\%)$ & $0,767 * *$ & $0,776 * *$ & $0,025 \mathrm{~ns}$ \\
\hline Massa de mil sementes puras (g) & $0,692 * *$ & $0,656 * *$ & $0,549 * *$ \\
\hline Germinação de sementes (\%) & $-0,024 \mathrm{~ns}$ & $-0,094 \mathrm{~ns}$ & $0,471 * *$ \\
\hline
\end{tabular}

** significativo a $1 \%$ de probabilidade pelo teste $\mathrm{F}$; *: significativo a 5\% de probabilidade pelo teste $\mathrm{F}$; NS: não significativo a 5\% de probabilidade pelo teste $\mathrm{F}$.

Fonte: Elaboração dos autores. 
De maneira geral, estes resultados são condizentes com os relatados na litearatura por Lordkaew et al. (2011) e por Lordkaew et al. (2013). Lordkaew et al. (2013), em arroz (Oryza sativa L.), verificaram que a aplicação de B influenciou sobre o vingamento de grãos e sobre o peso de grãos planta $^{-1}$, embora não tenham observado correlação entre o vingamento e o peso de grãos planta-1 com os parâmetros número de perfilhos planta $^{-1}$, porcentagem de perfilhos férteis e com a MS planta ${ }^{-1}$.

A correlação entre a massa de perfilho com panícula com as produtividades de sementes aparentes, puras e puras viáveis foi negativa e não significativa (Tabela 5). A correlação entre o número de perfilhos com panícula com a produtividade de sementes aparentes foi significativa e baixa. Os caracteres número de perfilhos com panícula e a $\mathrm{MS} \mathrm{ha}^{-1}$ não apresentaram correlação significativa com a produtividade de sementes puras e com a produtividade de sementes puras viáveis. Os números de sementes aparentes e puras, panícula ${ }^{-1}$ e área ${ }^{-1}$, a porcentagem de sementes puras, a massa de mil sementes puras e o índice de colheita foram correlacionados positivamente e significativamente com as produtividades de sementes aparentes, puras e puras viáveis. A germinação de sementes não teve correlação significativa com as produtividades de sementes aparentes e puras.

Tabela 5. Coeficiente de correlação de Pearson entre a massa de mil sementes puras (MMSP), massa de perfilho com panícula (MPP), porcentagem de perfilhos com panícula (PP), número de perfilhos com panícula (NPP), matéria seca (MS), número de sementes aparentes panícula ${ }^{-1}$ e número de sementes puras panícula ${ }^{-1}$, em capim-mombaça em função de épocas e doses de boro.

\begin{tabular}{|c|c|c|c|c|c|c|}
\hline Parâmetro & $\begin{array}{c}\text { MPP } \\
\left(\text { g MS perfilho }^{-1}\right)\end{array}$ & $\begin{array}{l}\text { PP } \\
(\%)\end{array}$ & $\begin{array}{c}\text { NPP } \\
\text { (perfilhos } \mathrm{m}^{-2} \text { ) }\end{array}$ & $\begin{array}{c}\text { MS } \\
\left(\mathrm{kg} \mathrm{ha}^{-1}\right)\end{array}$ & $\begin{array}{l}\text { NSAP } \\
\text { (sementes } 1\end{array}$ & $\begin{array}{c}\text { NSPP } \\
\text { anícula }^{-1} \text { ) }\end{array}$ \\
\hline MMSP (g) & $-0,050 \mathrm{NS}$ & $0,209 \mathrm{NS}$ & $0,092 \mathrm{NS}$ & $-0,025 \mathrm{NS}$ & $0,356 *$ & $0,246 \mathrm{NS}$ \\
\hline MPP (g MS perfilho-1) & & $-0,066 \mathrm{NS}$ & $-0,215 \mathrm{NS}$ & $0,076 \mathrm{NS}$ & $-0,040 \mathrm{NS}$ & $-0,030 \mathrm{NS}$ \\
\hline PP (\%) & & & $0,267 \mathrm{NS}$ & $0,215 \mathrm{NS}$ & $0,332 \mathrm{NS}$ & $0,128 \mathrm{NS}$ \\
\hline NPP (perfilhos $\mathrm{m}^{-2}$ ) & & & & $-0,140 \mathrm{NS}$ & $-0,106 \mathrm{NS}$ & $-0,238 \mathrm{NS}$ \\
\hline $\operatorname{MS}\left(\mathrm{kg} \mathrm{ha}^{-1}\right)$ & & & & & $0,108 \mathrm{NS}$ & $0,193 \mathrm{NS}$ \\
\hline
\end{tabular}

** significativo a $1 \%$ de probabilidade pelo teste $\mathrm{F}$; *: significativo a $5 \%$ de probabilidade pelo teste $\mathrm{F}$; NS: não significativo a $5 \%$ de probabilidade pelo teste $\mathrm{F}$.

Fonte: Elaboração dos autores.

Como não houve aumento no número de perfilhos com panícula, os incrementos nas produtividades de sementes puras e de puras viáveis foi obtido com o aumento no número de sementes puras panícula ${ }^{-1}$ e na massa de mil sementes puras, mostrando que houve efeitos compensatórios. Os coeficientes de correlações simples descrevendo as relações entre os números de sementes aparentes e puras área-1 com a produtividade de sementes aparentes, produtividade de sementes puras e com o índice de colheita, foram de magnitude próxima aos reportados por Barth Neto et al. (2010) e por Canto et al. (2012). As correlações significativas entre a porcentagem de sementes puras e a massa de mil sementes puras com as produtividade de sementes aparentes, puras e puras viáveis, obtidas neste trabalho, podem estar também associadas aos efeitos do B citados previamente que resultaram em melhoria no vingamento de sementes do capimmombaça.

\section{Conclusões}

As exigências de boro na cultura de sementes do capim-mombaça são distintas para o desenvolvimento de sementes, em relação ao crescimento vegetativo. 
A produção de sementes aparentes e puras, por panícula e por unidade de área, e a massa de mil sementes puras são beneficiadas com a aplicação foliar de boro no início de março.

A aplicação foliar de boro não apresenta efeitos consistentes sobre a pureza física e sobre a germinação de sementes.

Os caracteres que mais se correlacionam com as produtividades de sementes aparentes e puras são o índice de colheita e os números de sementes aparentes e puras por área. A massa de perfilho com panícula, o número de perfilhos com panícula, a matéria seca por unidade de área, o número de sementes puras por panícula e a massa de mil sementes puras não são correlacionados.

\section{Referências}

BARTHNETO,A.; BOLETA, V. S.; PANCERAJÚNIOR, E. J.; ALMEIDA, G. M.; CANTO, M. W.; GASPARINO, E.; BALTAZAR, L. F. Nitrogênio e época de colheita nos componentes da produtividade de forragem e sementes de capim-mombaça. Pesquisa Agropecuária Brasileira, Brasília, v. 45, n. 11, p. 1312-1320, 2010.

BELL, R. Diagnosis and prediction of boron deficiency for plant production. Plant and Soil, Heidelberg, v. 193, n. 1-2, p. 149-168, 1997.

BERGER, K. C.; TRUOG, E. Boron determination in soils and plants. Industrial \& Engineering Chemistry Analytical, v. 11, p. 540-544, 1939.

BRASIL. Ministério da Agricultura, Pecuária e Abastecimento. Regras para análise de sementes. Ministério da Agricultura, Pecuária e Abastecimento. Secretaria de Defesa Agropecuária. Brasília: MAPA/ ACS, 2009. p. 147-224.

BROWN, P. H.; BELlALOUI, N.; WIMMER, M. A.; BASSIL, E. S.; RUIZ, J.; HU, H.; PFEFFER, H.; DANNEL, F.; RÖMHELD, V. Boron in plant biology. Plant Biology, Berlim, v. 4, n. 2, p. 205-223, 2002.

CANTO, M. W. Dinâmica de crescimento e produção animal em capim Tanzânia adubado com doses de nitrogênio. 2003. Tese (Doutorado em Agronomia) Universidade Federal do Paraná, Curitiba.

CANTO, M. W.; BARTH NETO, A.; PANCERA JÚNIOR, E. J.; GASPARINO, E.; BOLETA, V. S. Produção e qualidade de sementes do capim-mombaça em função da adubação nitrogenada. Bragantia, Campinas, v. 71, n. 3, p. 430-437, 2012.

COCKSON, W. R.; ROWARTH, J. S.; CAMERON, K. $\mathrm{C}$. The response of a perennial ryegrass (Lolium perenne L.) seed crop to nitrogen fertilizer application in the absence of moisture stress. Grass and Forage Science, Oxford, v. 55, n. 4, p. 314-325, 2000.

COMISSÃO DE QUÍMICA E FERTILIDADE DO SOLO RS-SC. Manual de adubação e de calagem para os Estados do Rio Grande do Sul e Santa Catarina. Porto Alegre: Sociedade Brasileira de Ciência do Solo, 2004. $394 \mathrm{p}$.

CONDÉ, A. R.; GARCIA, J. Determinação da maturação fisiológica das sementes do capim-colonião (Panicum maximum Jacq.). Revista Brasileira de Sementes, Londrina, v. 14, n. 3, p. 181-185, 1985.

DELL, B.; HUANG, L. Physiological response of plants to low boron. Plant and Soil, Heidelberg, v. 193, n. 1-2, p. 103-120, 1997.

DIAS, M. C. L. L.; ALVES, S. J. Avaliação da viabilidade de sementes de Panicum maximum Jacq. pelo teste de tetrazólio. Revista Brasileira de Sementes, Londrina, v. 30, n. 3, p. 152-158, 2008.

GUERTAL, E. A. Boron fertilization of Bentgrass. Crop Science, Madison, v. 44, n. 1, p. 204-208, 2004.

GUPTA, U. C. Boron. In: BARKER, A. W.; PILBEAM, D. J. (Ed.). Handbook of plant nutrition. Boca Raton: CRC Press, 2004. p. 241-278.

JANK, L.; RESENDE, R. M. S.; VALLE, C. B.; RESENDE, M. D. V.; CHIARI, L.; CANÇADO, L. J.; SIMIONI, C. Melhoramento genético de Panicum maximum. In: RESENDE, R. M. S.; VALLE, C. B. do; JANK, L. (Ed.). Melhoramento de forrageiras tropicais. Campo Grande: Embrapa Gado de Corte, 2008. p. 55-87.

LORDKAEW, S.; DELL, B.; JANJOD, S.; RERKASEM, B. Boron deficiency in maize. Plant and Soil, Heidelberg, v. 342, n. 1-2, p. 207-220, 2011.

LORDKAEW, S.; KONSAENG, S.; JONGJAIDEE, J.; DELL, B.; RERKASEM, B; JANJOD, S. Variation in responses to boron in rice. Plant and Soil, Heidelberg, v. 363, n. 1-2, p. 287-295, 2013.

MARSCHNER, H. Mineral nutrition of higher plants. London: Academic Press, 1995. 889 p.

MIWA, K.; FUJIWARA, T. Boron transport in plants: coordinated regulation of transporters. Annals of Botany, Oxford, v. 105, n. 7, p. 1103-1108, 2010.

MISRA, S. M.; SINHA, N. C.; TOMER, P. S. Seed yield of sorghum grown in an alfisol, in relation to 
boron nutrition at the reproductive phase. Plant and Soil, Heidelberg, v. 132, n. 2, p. 293-296, 1991.

MONTEIRO, J. M. C.; FAVORETTO, V.; REIS, R. A. Épocas de rebaixamento e níveis de nitrogênio na produção e qualidade de sementes de capim-colonião. Pesquisa Agropecuária Brasileira, v. 19, p. 545-552, 1984.

MUIR, J. P.; JANK, L. Guineagrass. In: MOSER, L. E.; BURSON, B. L.; SOLLENBERGER, L. E. (Ed.). Warm-season $\left(C_{4}\right)$ grasses. Madison: American Society of Agronomy, Crop Science Society of America, Soil Science Society of America, 2004. p. 589-621.

OERTLI, J. J.; LUNT, O. R.; YOUNGNER, V. B. Boron toxicity in several turfgrass species. Agronomy Journal, Madison, v. 53, n. 4, p. 262-265, 1961.

PETERSON, L. A.; NEWMANN, R. C. Influence of soil $\mathrm{pH}$ on the availability of added boron. Soil Science Society of American Journal, Madison, v. 40, n. 2, p. 280282, 1976.

REISENAUER, H. M.; WALSH, L. M.; ROEFT, R. G. Testing soils for sulphur, boron, molybdenium, and chlorine. In: WALSH, L. M.; BEATON, J. D. (Ed.). Soil testing and plant analysis. Madison: Soil Science Society of America, 1973. p. 173-200.

RERKASEM, B.; JAMJOD, S. Boron deficiency in wheat: a review. Field Crops Research, Amsterdam, v. 89, n. 2-3, p. 173-186, 2004.

ROSOLEM, C. A.; BÍSCARO, T. Adsorção e lixiviação de boro em Latossolo Vermelho-Amarelo. Pesquisa Agropecuária Brasileira, Brasília, v. 42, n. 10, p. 14731478, 2007.
SANTOS, H. G. dos; JACOMINE, P. K. T.; ANJOS, L. H. C. dos; OLIVEIRA, V. A. de; OLIVEIRA, J. B. de; COELHO, M. R.; LUMBRERAS, J. F.; CUNHA, T. J. F. Sistema brasileiro de classificação de solos. Rio de Janeiro: Embrapa Solos, 2006. 306 p.

SHORROCKS, V. M. The occurrence and correction of boron deficiency. Plant and Soil, Heidelberg, v. 193, n. 1-2, p. 121-148, 1997.

SOARES, M. R.; CASAGRANDE, J. C.; ALLEONI, L. R. F. Adsorção de boro em solos ácricos em função da variação do pH. Revista Brasileira de Ciência do Solo, Viçosa, v. 32, n. 1, p. 111-120, 2008.

STATISTICAL ANALYSIS SYSTEM INSTITUTE SAS Institute. SAS user's guide: statistics. Cary: SAS Institute, $2002.419 \mathrm{p}$.

TORRES, B. M. J.; CANCINO, S. J.; HERNANDEZGARAY, A.; PÉREZ, J. P. Efecto de la fertilización nitrogenada sobre el rendimiento y calidad de semilla de pasto guinea. Técnica Pecuaria en México, Mérida, v. 47, n. 1, p. 69-78, 2009.

YAU, S. W.; RYAN, J. Boron toxicity tolerance in crops: a viable alternative to soil amelioration. Crop Science, Madison, v. 48, n. 3, p. 854-865, 2008.

WONGMO, J.; JAMJOD, S.; RERKASEM, B. Contrasting responses to boron deficiency in barley and wheat. Plant and Soil, Heidelberg, v. 259, n. 1-2, p. 103110, 2004.

WREGE, M. S.; STEINMETZ, S.; REISSER JÚNIOR, C.; ALMEIDA, I. R. Atlas climático da região sul do Brasil. Estados do Paraná, Santa Catarina e Rio Grande do Sul. Pelotas: EMBRAPA, 2011. 333 p. 
